\title{
USE OF AUGMENTED REALITY IN SOCIAL SCIENCES AS EDUCATIONAL RESOURCE
}

\author{
Dr. Purificacion TOLEDO-MORALES \\ Faculty of Education, University Seville \\ Seville, Spain \\ Dr. Jose Manuel SANCHEZ-GARCIA \\ Faculty of Education, University Seville \\ Seville, Spain
}

\section{ABSTRACT}

This study investigated the effects of the use of Augmented Reality (AR) on the academic performance of students, as well as perceptions that were following the use of this new technology resource. The participants were students of primary education in Spain, which were assigned to an experimental group and a control group. Contents related to the topic Representation Earth were created, and were held with the collaboration of teachers using tablets to display bookmarks. To analyze the results collection tools of quantitative and qualitative data are used, a pre-test and post-test on the subject explained. I was done and Likert questionnaire on aspects of the use of the AR was given and an in depth interview was done teachers. Used tools of collection of data quantitative and qualitative to the deal are of a design quasi-experimental. In order to analyze the data, the statistical software SPSS 23 was used. The use of the AR as a teaching tool sheds results that reveal that the performance and the acquisition of knowledge of students improves significantly, being reflected in the ratings that were higher. The process of teaching and learning is perceived as positive, incentive and facilitator in the acquisition of knowledge.

Keywords: Augmented reality, elementary education, integration of technology, teaching/learning process.

\section{INTRODUCTION}

The evolution of information and communication technologies shows each certain time advances that can consider novel, many of them hide a long adaptation from others areas: of research, business or military, until its adaptation to the use of the great public, and in the same process to the educational field. One of these is the augmented reality (AR) that in these moments begins to implement is in the educational field and that presents numerous possibilities in presentation of content and the way of encourage to them students (Tanner, Karas, \& Schofield, 2014). There are clear definitions about what AR is the best known are those of Azuma (1997) pioneer in the study of this technology, and having in common the of the superimposition of elements generated by the computer to reality, real, in three dimensions and whose vision is mediated by an electronic device with camera and internet (Wu, Lee, Chang, \& Liang, 2013; Tanner, Karas, \& Schofield, 2014; Holley, \& Howlett, 2016).

Although the basis for the use of AR is a few years ago, the possibilities for its effective application in educational settings have not been given until recent dates. The cheapening of the costs of mobile devices such as telephone, tablets and computers 
equipped with a camera and Internet connections allows for their use in the educational environment. Experiences such as those of Huang, $\mathrm{Li}$, \& Fong (2015) allow us to understand how it will be implemented and what its benefits are.

This study covers from the creation of the materials that are used in the classroom until its use, with the main objective being to understand the complete process for its implantation and the impact on the students when interacting with the ICT and with the $A R$ in particular. This paper analyzes the way in which it implants in our educational field, how the contents are created and its use in the teaching of a Social Science theme for five weeks. The theme "The Representation of the Earth" was chosen in collaboration with the professors, within the syllabus of the subject. It proceeded to the creation of ad hoc contents by means of the use of programs of AR. In the classroom these contents were visualized by pairs of students through the use of tablets.

The objectives of this work are to know if the use of AR tools in the teaching and learning process favors the acquisition of knowledge by students, compare if the ratings improve using these technologies as well as explore the perceptions of students and teachers when using AR in their classrooms. Is remarkable the interest woken up in the students who perceives an extra motivation that is not present in the classes in which it did not use the AR, favoring the process of teaching and learning and the comprehension of the contents, aspect that we can see reflected in the improvement of the ratings of the groups that use AR.

\section{THEORETICAL FRAMEWORK}

The Augmented Reality (AR) is emerging as one of the technological advances that transform education, presenting potentially relevant contributions when presenting content to our students. Of the same mode exists the perception that the use of ICT improves the process of teaching and learning and them skills technological of students and teachers (Wu, Lee, Chang, \& Liang, 2013; Badia, Chumpitaz, Vargas, \& Suarez, 2016; Holley, \& Howlett 2016). For Azuma (2010) the AR allows that the real and the virtual coexist in the same space, giving the possibility to interact with these elements in real time. It allows us to show information by providing multimedia or texts related to objects or places, in a simple and immediate (Billinghurst, Kato, \& Poupyrev, 2001).

So can successfully implement the needed technologies that are currently found in many mobile devices, some of them quite affordable. It is common for mobile phones, the Tablet and laptops allow access to technologies such as GPS, internet, camera, audio, giving the option of installing software with easy to use user interfaces. This has been used in various areas of life from the advertising that is having a big impact, reaching used in games of various kinds (Del Moral, Villalustre, \& Neira-Pinero, 2016; Laine, Nygren, Dirin, \& Suk, 2016).

\section{Multidisciplinary Use of AR}

There are many authors that show which disciplines can be used the AR, medicine, design, entertainment, tourism, games network (with the global impact of Pokemon Go) and mentioning the field that compete us, education. Huang, $\mathrm{Li}, \&$ Fong (2015) collect multiple experiences around the world of the interaction of the students with the AR in the different stages of education in different subjects: teaching language, biology, foreign languages... in all the curriculum in some cases. Or as Huang, Chen, \& Chou (2016) studies that used the AR to environmental education. The use of this technology permeates all phases of education, being especially motivating and fostering autonomous learning (Martín-Gutierrez, Fabiani, Benesova, Meneses, \& Mora, 2015) in upper stages, featuring improvements over traditional teachings in terms of involvement and motivation (Di Serio, Ibanez, \& Kloos, 2013). Similarly, there are numerous applications that we find for the use of the AR in everyday life, increasing almost daily the number of applications that you can download to our devices. More limited are those used in the classrooms of history and social sciences being many of them pay or linked to editorials. 
The integration of these resources is taking to cape in all the world can find exponents of them in various studies. Some examples for our environment arise from investigations such as Prendes (2015) that analyses the context of production and use of the AR, appearing as relevant in our educational environment, with experiences like Wasko (2013) and Cheng \& Tsai (2016), or projects that geo located information for purposes of training or tourist. The AR is present in the networks and can be considered fluent communication of experiences in our educational environment, although its development and dissemination is dependent on their own classrooms and presentation on Blogs and Web centers or instructors, still present on pages such as http://www.educaciontrespuntocero.com or http://www.enlanubetic.com.es, there are many more. Similarly, we can find projects of use of AR in the international level and that we can use as inspiration when applying or replicating experiences in our classrooms.

\section{Experiences of AR in the Classroom}

We find that AR is used in non-educational environments in which it reports benefits; Ruiz-Ariza, Casuso, Suarez-Manzano, \& Martínez-Lopez (2017) perceive significant profits in the cognitive performance and emotional intelligence with the use of Pokemon Go. We also find it in the industrial field, in which the advantages and disadvantages of its use have been analyzed, and the degree of maturity of this technology for its implantation (Palmarini, Erkoyuncu, Roy, \& Torabmostaedi, 2018).

For use in education we find valuable examples in classrooms around the world. Giasiranis \& Sofos (2017) in the teaching of the topic "Representation of information in computers" determine that the use of AR has an added value in education, and contribute to improving performance with positive effects in the teaching and learning processes. For a better understanding of implantation in primary classrooms, Alkhattabi (2017) combines the use of observation and survey using the Technology Acceptance Model (TAM), and evaluates the use of AR by primary school teachers when finding in their classrooms to digital natives who demand the adoption of these technologies. The use of $A R$ in the classroom makes the learning process more active, effective and meaningful, interested researchers and is well accepted by users, both students who perceive the benefits of their use, as teachers who have the will to use it and have already acquired skills in technologies that motivate them to use them.

In other cases, the use of AR and traditional methods does not show differences as in the work made by Gun \& Atasoy (2017), on the subject of sixth degree "Geometrical objects and volume of measurement" using a design quasi-experimental that compares the data obtained of a group control and an experimental group, in which they used real objects in the first case and AR in the second. Its use in secondary education in the Chemistry classrooms analyzed by Chang \& Chung (2018) improves the students' understanding of the macro and microscopic world of Chemistry by improving the effects of learning and reaching the conclusion that $A R$ can be integrated positive way in teaching and intervenes in the improvement of grades. These examples show how AR is being integrated into classrooms around the world and in all areas of knowledge. In some cases with greater benefits than in others.

\section{METHODOLOGY}

\section{Participants}

The participants in this study were 49 students from two classes of $5^{\text {th }}$ of elementary education in a school in the province of Seville (Spain). The age of student ranged between 10 and 11, of which 22 were women and 27 men. The experimental group was $5^{\text {th }} A$, composed of 25 students of which $11(45 \%)$ were women and $14(55 \%)$ males, with which tools of AR was used. The control group was $5^{\text {th }}$ B composed of 24 students, $11(33 \%)$ were women and $13(67 \%)$ men, with those who used a traditional method of teaching. 


\section{Design}

This study was conducted on the course academic 2016-17 following methodology quantitative and qualitative. Methodologically it responds to a research design quasiexperimental where he applied a pre-test and post-test to an experimental group and a control group with the goal of studying whether the use of the AR as independent variable (IV) influence in the acquisition of knowledge and learning as the dependent variable (DV).

The objectives in this study were:

$>$ Find out if the use of AR as a technological tool in the teaching and learning process promotes the acquisition of knowledge and improve the performance of students.

$>$ To compare the qualifications of students before and after the use of AR as a teaching tool.

$>$ To explore the perceptions of students has the use of the AR as a teaching tool.

\section{Materials}

With the purpose of perform this study properly contacted teachers in two classrooms that we reported what were the subjects that were taught at the time where he was going to carry out the investigation in their school. The given topic was "Representation of the Earth ", for which content ad hoc was created. For the realization of this work were available to classrooms 15 Tablets of mid-range which had some problems when using them to display contents of AR, including the do not display, access errors to the camera of the device with some applications, the information recorded by the gyroscope of device which presented information to reverse failure, or in a direction contrary to that performed is the display.

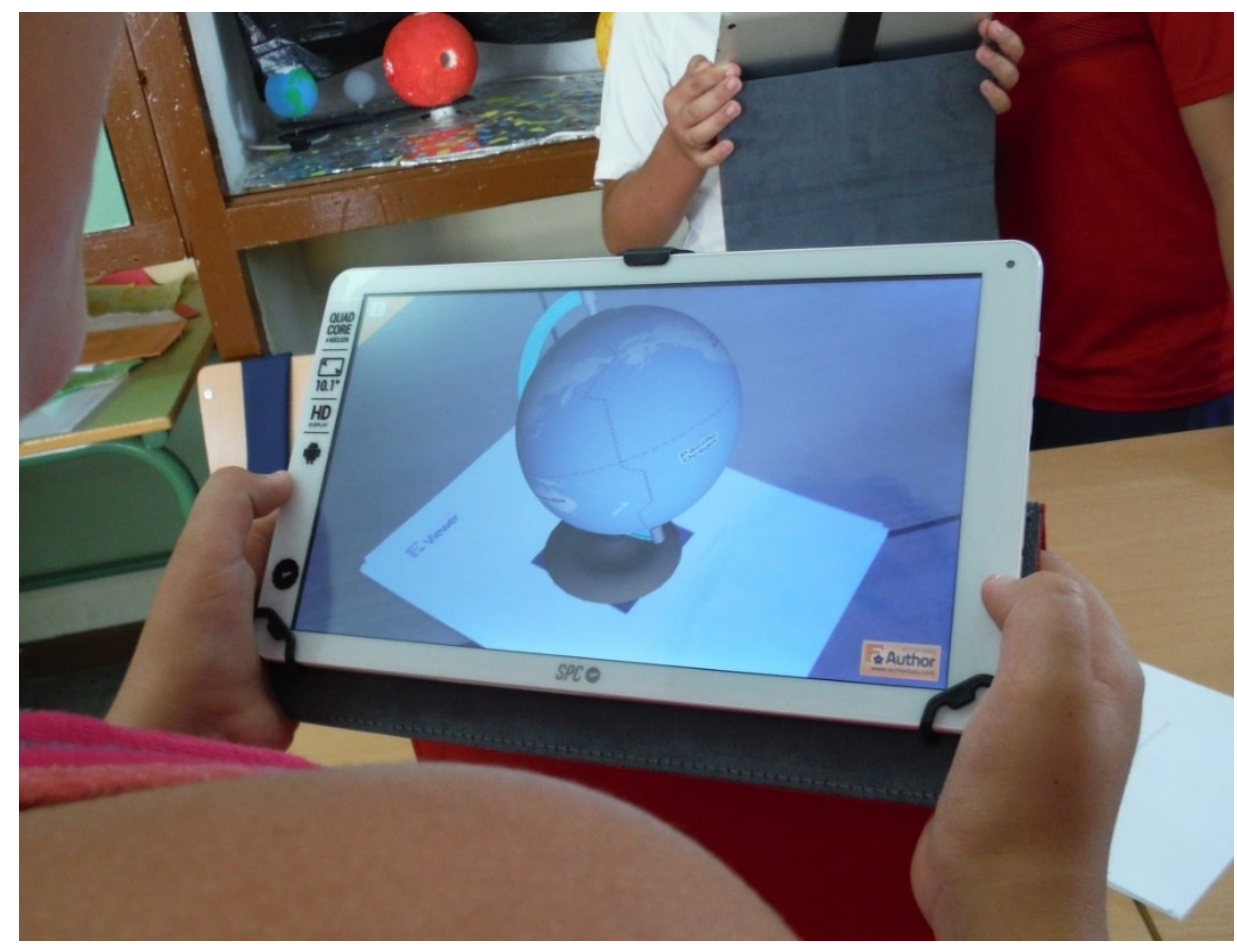

Figure 1. Example of Representation of the Earth, Hemispheres in AR

It was decided to use of free version of Aumentaty Author, with which they were made the contents of Aumentaty Viewer for use in devices by the students in these programs to be the most compatible. This program allows you to preload the contents which facilitated its use not necessary to crap content from the network, limited due to the low bandwidth of school (see Figure 1 and Figure 2). 


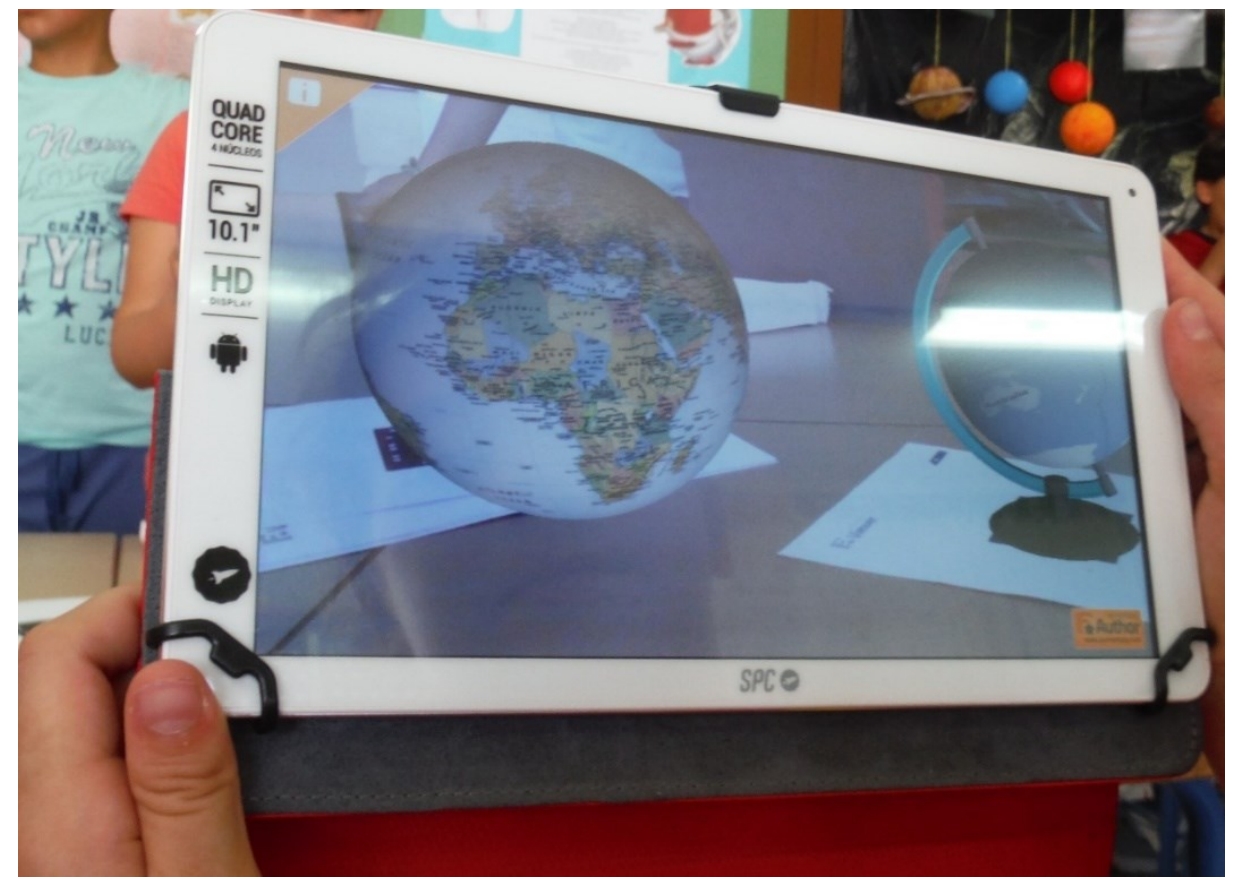

Figure 2. Example of Representation of the Earth, Political Map.

For immersion in the classroom of elements of AR is followed guidelines for teachers of both groups, presenting content that was the theme in its two aspects, mechanisms and structures, performing a timing of the use of elements that do not break the teaching style of teachers, trying to insert the AR in the classroom in a natural way and altering as little as possible, the behavior of the students in the classroom to be present technological elements innovative and minimizing the presence of researchers.

\section{Procedures}

The procedure followed in this research is divided into five phases and was the following:

$>$ Pre-test phase. A pre-test was administered to the control group and the experimental to assess the level of knowledge on the subject that he would teach, which was social sciences.

$>$ Learning phase. Is explained to the group $5^{\text {th }} A$ (experimental) the theme of science social "the representation of the Earth", using those materials previously created of AR and that were displayed in couples with Tablet. The lesson of the $5^{\text {th }} B$ group (control) was explained in a traditional manner without AR. Development of the theme and activities were developed in three weeks with the hours established by the school. He was explained to the students that in the next week would be a test to learn what had learned explained topic.

$>$ Post-test phase. Once the theme concluded passed the post-test both the experimental group and control, so if you had or not used the contents of AR, in order to know if the use of AR influenced in the knowledge of the subject explained with or without AR. It served to quantify the average degree of learning achieved by both groups. The test time was $\mathbf{2 0}$ minutes.

$>$ Stage of perception of use of the AR in teaching. Once they concluded the theme were passed to students in the experimental group $\left(5^{\text {th }} A\right)$ a brief questionnaire of 16 items, which were valued on a Likert-type scale the perceptions of students in the use of AR in the teaching-learning process.

$>$ Phase of interviews. The last phase consisted of interviewing the students in the experimental group about their feelings and opinions during the learning process in which we used the AR. Also he interviewed the teacher about the use of AR in the process of teaching and learning. 


\section{Data Collection Instrument}

In this study, quantitative and qualitative data collection tools data were used. First the pre-test and post-test were used to obtain the scores of students before and after explaining the subject in the classroom. And a questionnaire was also used to obtain information on perceptions of the use of AR in the process of teaching and learning.

The pre-test and post-test it was exam type multiple choice test, consisting of ten questions and three answers of which only one was valid, with which was obtained ratings of 0 to 10. The questionnaire was developed from the Technology Acceptance Model (TAM) (Davis, 1989; Venkatesh, \& Bala, 2008), with the object to collect information about the opinions of students regarding the use of AR in the classroom experience. 16 items in the questionnaire Likert-type with five levels of responses was composed of five dimensions (see Table 1), they are: utility perceived (UP), ease of use (EU), enjoy perceived (EP), attitude of use (AU) and intent of use (IU). Analysis of reliability of the questionnaire gave a Cronbach alpha of 0.858 .

Table 1. Dimensions of the Questionnaire of Perception of the Use of AR

\begin{tabular}{ll}
\hline Dimension & Definition \\
\hline Utility Perceived (UP) & $\begin{array}{l}\text { Grade in that a student estimated that the use of the AR } \\
\text { would improve their learning and get draw better ratings. } \\
\text { Extent to which the use of the AR is perceived as easy and } \\
\text { does not require great efforts. } \\
\text { Degree in which the use of the AR is perceived as } \\
\text { pleasant. } \\
\text { Positive or negative sentiment regarding the use of the } \\
\text { AR in class. } \\
\text { Grade in which the student formulates plans to use or not } \\
\text { the AR in the future. }\end{array}$ \\
Antitude of Use (AU) & \begin{tabular}{l} 
Intent of Use (IU) \\
\hline
\end{tabular}
\end{tabular}

\section{DATA ANALYSIS}

The data obtained from the administration of the pre-test and post-test received different analysis with the statistical package SPSS 23.0. In first place, is proceeded to the analysis descriptive of mean and frequencies to know the features of the samples. Secondly, the test t-student to was used to compare the two groups (control and experimental) in order to check if the use of the AR improved the performance of students. On the one hand is compared the group control before and after teach the theme, by another is compared the group experimental before and after give the theme with $A R$, and in third place is compared the group control and experimental at the level of pre-test and subsequently at the level of post-test.

Also were the means and standard deviations of $\mathbf{1 6}$ items in the questionnaire collecting information of the perceptions of students regarding the use of AR as technology in the teaching and learning process. The reliability of the questionnaire was measured through the internal consistency between items and Cronbach's alpha coefficient was obtained.

The qualitative data collected from interviews were analyzed using content analysis method. During the analysis process, data first were coded and categories and subcategories (see Figure 3) were found. In the data analysis frequencies, they were used, and thus, qualitative data collected were expressed numerically to make them more understandable (Dundar, \& Akcayir, 2012). 


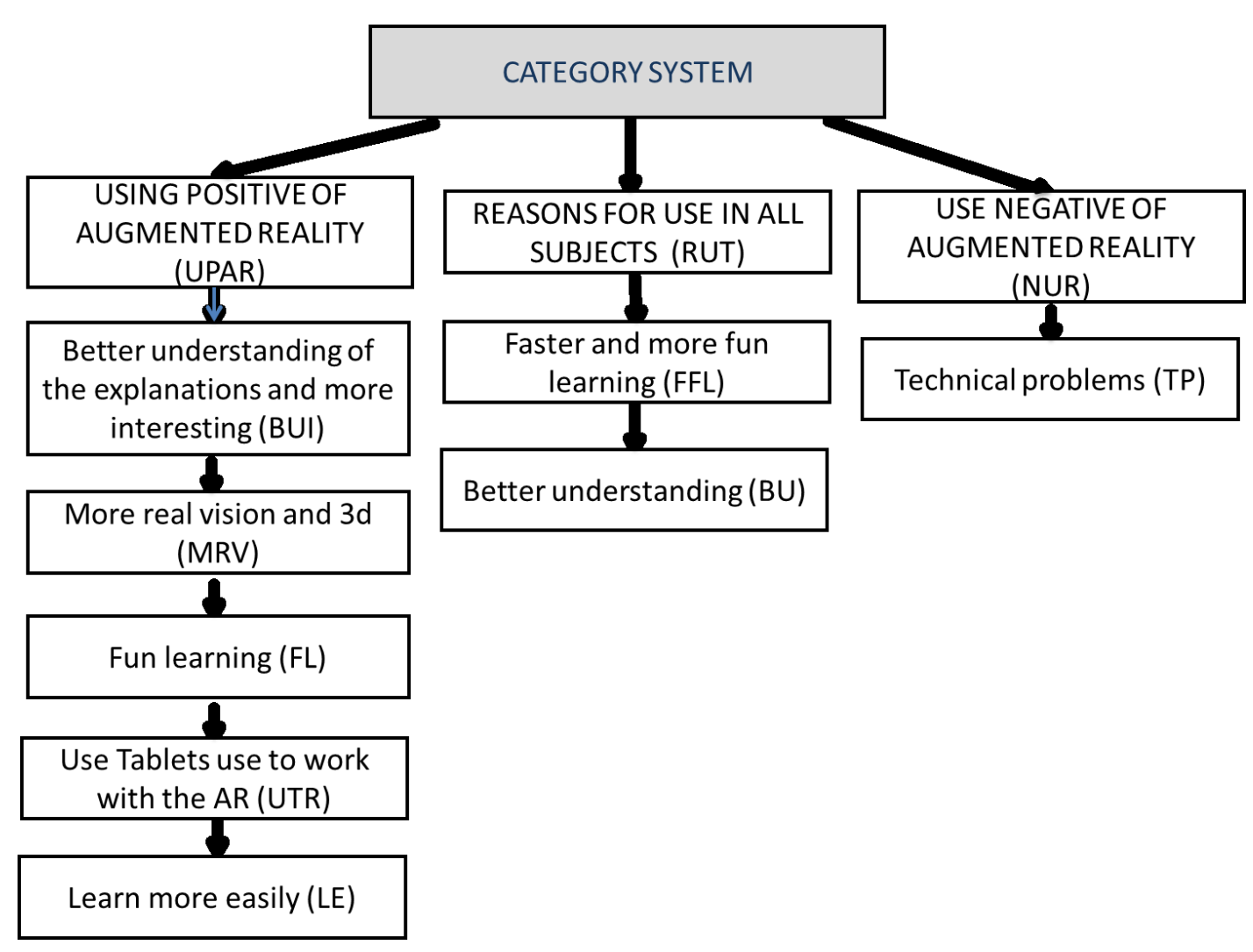

Figure 3. Schematic of categories and subcategories

\section{RESULTS}

The results obtained in the study were of two types: (a) the level of learning achieved by both groups of students to ensure that the use of technologies of AR in teaching was favorable being reflected in better ratings and (b) the perceptions students in the experimental group had the use of AR during the teaching in class.

\section{Acquisition of Knowledge and Improving the Academic Achievement}

Level of learning achieved by the experimental group after the application of AR was reflected in the qualifications obtained in the post-test. Figure 4 shows the differences between the qualifications obtained by the experimental group in the pre-test and posttest. The results of test t-student of the pre-test and post-test of the experimental group obtained with the SPSS indicated that students score higher after the use of the technology of AR in the teaching and learning process, because the average obtained with the pre-test is 3.4 and the post-test 7.9, with a difference of 4.5 points more. Figure 4 shows that a large number of students passed with good grades the theme of social science explained with AR technology. $36 \%$ of students obtained qualification of outstanding and remarkable notable, $8 \%$ of good and $20 \%$ of approved. There was no suspense. 
The Earth

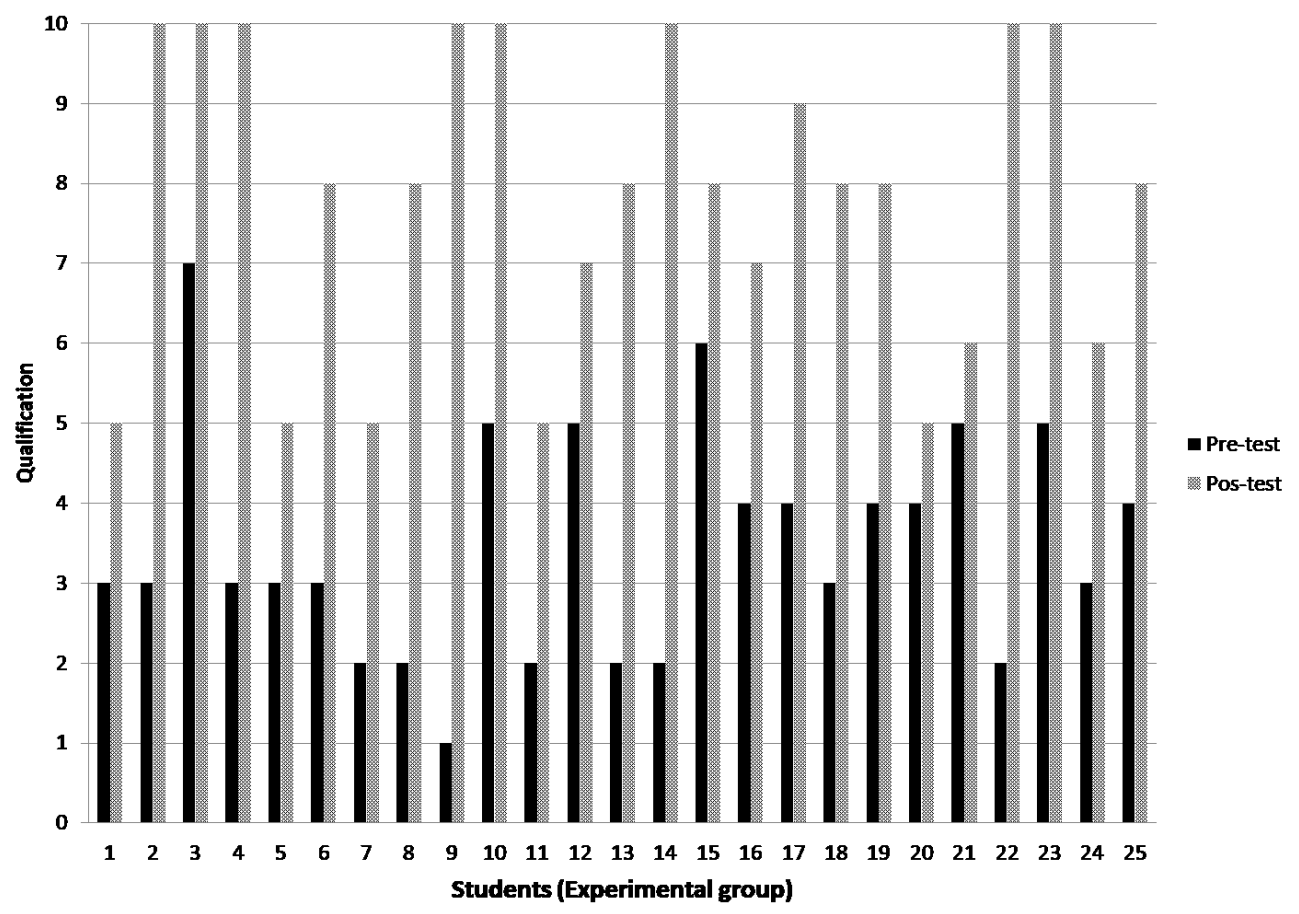

Figure 4. Qualifications obtained in the pre-test and post-test of the group experimental

Applying test t-student to the pre-test and post-test of the group control is obtained ratings a little higher after the explanations of the topic following a traditional method but the difference between the average is a little lower, 3.2 , in the pre-test the average rating was 3.2 and the post-test 6.4. Figure 5 shows how ratings from the control group in the post-test after the explanation of the subject are a bit higher, having a $21.5 \%$ of suspended students, $21 \%$ were outstanding, $24 \%$ notables, $12 \%$ good and $21.5 \%$ approved.

The Earth

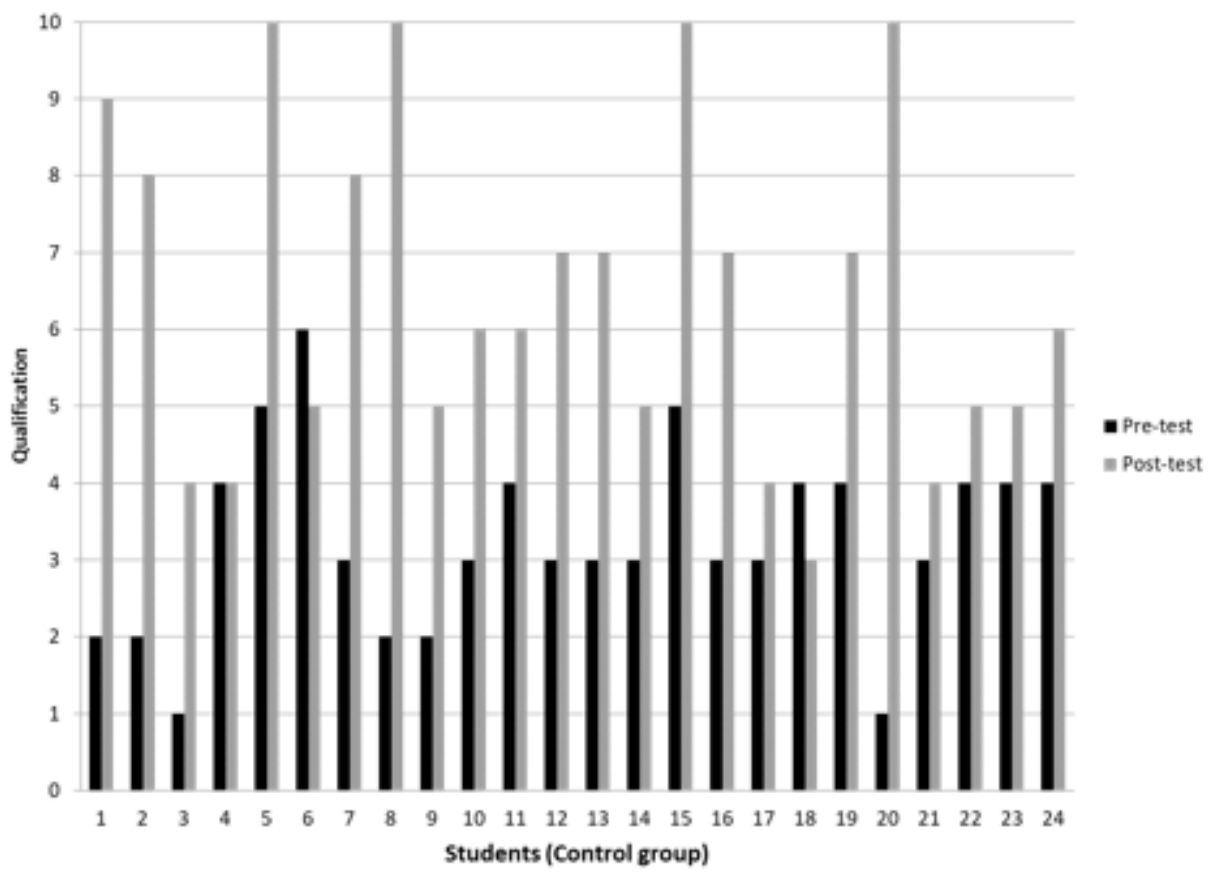

Figure 5. Qualifications obtained in the pre-test and post-test control group 
In this same line, Figure 6 showing the results of the test $t$ of the pre-test of the control group and the experimental group indicated that the experimental group $(M=3.4)$ obtained ratings slightly higher than the group control $(M=3.2)$ even before using tools of $A R$, with a difference of 0.2 score. And those obtained in the post-test of both groups also said that the group experimental obtained qualifications more high $(M=7.9)$ that the group control $(M=$ 6.4), with a difference of score of 1.5 , more high that it obtained in the pre-test.

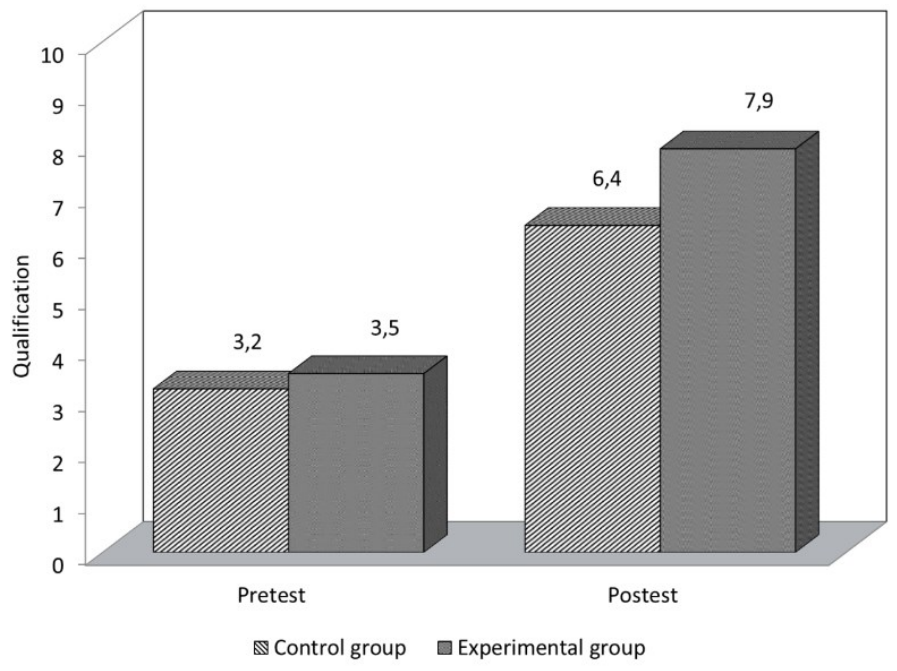

Figure 6. Comparison of the pre-test and post-test of the experimental group and control

\section{Perception and Opinion Regarding the Use of AR}

In accordance with them results obtained, the opinion of them students of $5^{\text {th }}$ to (experimental group) have had on the use of the AR as a technology that facilitates the learning and the understanding of the content is positive, since to features general them answers in them different items reached values of them middle above 3 except the item 13, which referred to the students were bored in class when used the $A R$, whose value was 1.86 , which meant that on the contrary not where they bored with its use, and item 2 which refer to take better grades when using the AR in classroom, with a value of 2.69. In relation to the dimensions and items of the questionnaire, the different results obtained from the experimental group can be consulted in table 2 and Figure 7.

Table 2. Mean scores and standard deviations obtained for Perceptions of the use AR

\begin{tabular}{|lll}
\hline & Mean & \multicolumn{1}{c}{ SD } \\
\hline Utility Perceived (UP) & 3.3304 & .75705 \\
I learn better when used in class AR. & 3.1739 & 1.11405 \\
I get better grades when used in class AR. & 2.6957 & .70290 \\
I understand better explanations of class with the AR. & 3.0435 & 1.39734 \\
The AR is helpful when you are learning. & 4.0000 & 1.04447 \\
The use of the AR increases my desire to work in class. & 3.7391 & 1.21421 \\
Ease of Use (EU) & 4.2899 & .70571 \\
The AR is easy to use. & 4.3043 & 1.01957 \\
Use the AR is not a problem for me. & 4.3913 & .98807 \\
I understand how to use the AR in class. & 4.1739 & 1.02922 \\
Enjoy Perceived (EP) & 4.4493 & .57392 \\
Use the AR in class is fun. & 4.7826 & .51843 \\
I liked to use AR in class. & 4.6522 & .64728 \\
Use the AR me allows you to learn playing. & 3.9130 & 1.20276 \\
Attitude of Use (AU) & 3.0145 & .60702 \\
The AR makes learning more interesting and exciting. & 3.6522 & 1.26522 \\
I get bored using AR in class. & 1.8696 & 1.39167 \\
I think that using the AR is a good idea. & 3.5217 & 1.34400 \\
Intent of Use (IU) & 3.6739 & 1.28460 \\
I would like to reuse the AR in class if I had opportunity & 3.9130 & 1.31125 \\
I would like to use the AR to learn other subjects. & 3.4348 & 1.67403 \\
\hline
\end{tabular}


The first five items of the questionnaire were targeted to obtain information on the level of perception of students in relation to the usefulness of use of AR perceived in the teaching-learning process. As can see in the table 2, those students perceived to levels average the utility of it AR, with an average of 3.33. The results obtained in that dimension items have highlighted students: "Learn best when used in class AR" ( $M=$ 3.17) which were $30 \%$ agree and disagree $39 \%$, "They get better grades when used in class AR" ( $M=2.69$ ) with those who were $13 \%$ agree and disagree $44 \%$, the $30 \%$ of the students said be in accordance with that "understands better the explanations of class with the AR" ( $M=3.04$ ) and the $35 \%$ are in disagreement, the $44 \%$ perceived be completely in accordance with that "the AR is useful when is learning" $(M=4)$, on the other hand the $30 \%$ is completely of agreement and the $35 \%$ of agreement that "the use of the AR increase their desire of work in class" $(M=3.73)$.

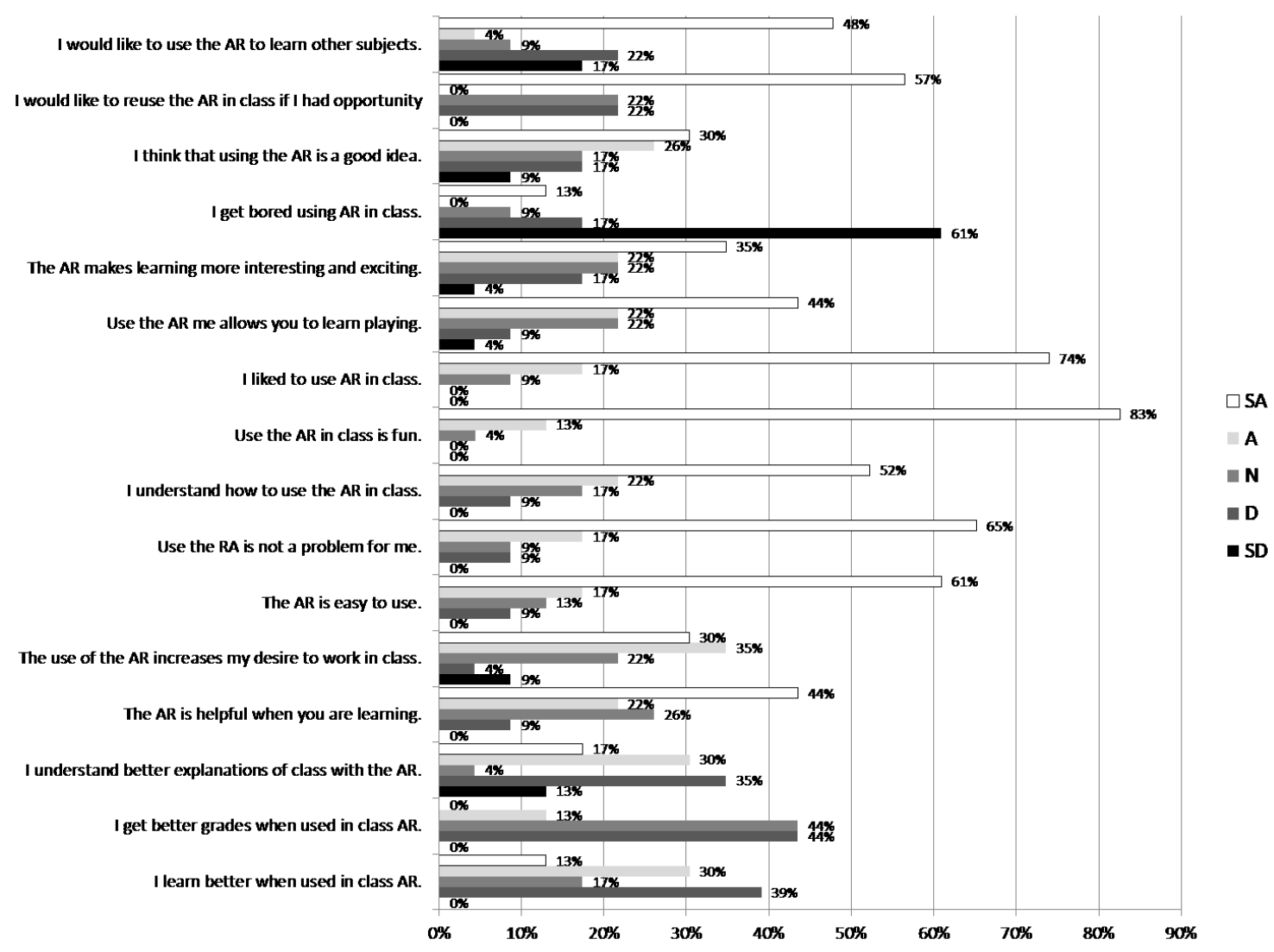

Figure 7. Perceptions of the experimental group the use of AR

With regard to the dimension ease of use of $A R$, as can see in the Figure 7, was very high the average obtained in the level of perception of them students, with value of 4.28. The three items of this dimension also reached very high averages, which indicated: that students perceived that "AR is easy-to-use" ( $M=4.30)$, "use AR is not a problem for them" $(M=4.39)$ and that "understands how to use the AR in class" $(M=4.17) .61 \%$ were fully in accordance with its ease of use, $65 \%$ with lack of problem to use it, and $52 \%$ with understanding how to use it in class.

The dimension perceived enjoy the use of the AR in the teaching process also obtained very high average scores $(M=4.44)$, as well as the three items of the same, which meant that students perceived that: "Using AR in class is fun" $(M=4.78)$ which $83 \%$ were fully agreed, liked using $A R$ in class $(M=4.65)$ were $74 \%$ completely agree and $44 \%$ were fully in agreement and 22 per cent in accordance with that "use AR allows them to learn by playing" ( $M=3.91)$. 
Dimension referring to the attitude of use of the AR obtained an average of 3.01, which meant from the results in the items that: $35 \%$ of the student body was fully in agreement and 22 percent agreed that "the AR makes learning more interesting and exciting" ( $M=$ $3.65), 61 \%$ completely at odds that the use of the $A R$ is bored in class $(M=1.86)$ and $30 \%$ completely agree and the $\mathbf{2 6 \%}$ agree in believing that it is a good idea the use of AR in class $(M=3.52)$. Finally it perception of it dimension intent of use also obtained values above it average $(M=3.67)$, which make reference to: the $57 \%$ of the students is completely in accordance with "I would like to return to use it AR in class if had opportunity" ( $M=3.91)$ and the $48 \%$ also were completely in accordance with "I would like to use the AR for learn others themes" $(M=3.43)$.

\section{Categorical Analysis of the Interviews}

As shown in Table 3 students perceive the use of AR in a positive way, $72 \%(f=18)$ students expressed the view that it was see and work with the Tablet, $48 \%(f=12)$ learn everything in a way more fun and easy. The same percentage appreciates that they better understand the explanations and that with this technology they seem more interesting, $48 \%$ of students opine that the AR allows them to see it very real and from and from different perspective and 3D and $40 \%(f=10)$ that learning is more fun. Regarding the reasons for using $A R$ in all subjects, $100 \%$ of the students think that they tend to be better, and only $32 \%(f=8)$ perceive that learning is faster. As for the negative use of AR in the classroom we find some displeasure with the technical problems posed by the use of AR (8\%).

Table 3. Qualitative Analysis of the Interviews of Students

\begin{tabular}{llll}
\hline Categories & SubC & \multicolumn{2}{l}{ Students } \\
\cline { 3 - 5 } & & $\boldsymbol{f}$ & $\%$ \\
\hline UPAR (Using positive of AR) & UTR (Use Tablets to work with AR) & $\mathbf{1 8}$ & $\mathbf{7 2}$ \\
& LE (Learn more easily) & $\mathbf{1 2}$ & $\mathbf{4 8}$ \\
& BUI (Better understanding of the & $\mathbf{1 2}$ & $\mathbf{4 8}$ \\
& explanations and more interesting) & & \\
& MRV (more real vision and in 3D) & $\mathbf{7}$ & $\mathbf{2 8}$ \\
RUT (Reasons for use in all & FL (Fun learning) & $\mathbf{1 0}$ & $\mathbf{4 0}$ \\
topics) & FFL (Faster and fun learning) & $\mathbf{8}$ & $\mathbf{3 2}$ \\
NUR (Negative use of AR) & BU (Better understanding) & $\mathbf{2 5}$ & $\mathbf{1 0 0}$ \\
\hline
\end{tabular}

To know the perceptions that teacher has of the use of AR and to what problems is faced for its use is made open in-depth interview in which he said the incentives and capability of this technology and the possibilities that presents at the time of integrate it in the classroom. He was at all times ready to use and integration, regretting that it is limited to a few sessions and a single subject. Before the possibility of continued use it seemed well although not for all subjects and topics, considering that this methodology not is conformed to some materials and content according their opinion, as language, math or physical education.

Although it welcomed this initiative was not it considered formed to create the content related to the AR, process that was complex, the same being so desirable that these contents are provided by publishers and out of easy implementation in the classroom. Also said that would accept receiving training on this type of technology always in its schedule of work and in its own School. Regarding the use of Tablet or mobile for Education considers it problematic and far away for use at this stage.

\section{DISCUSSIONS}

After analyzing the results of the pre-test and post-test of the experience in a 5th grade classroom using AR applied to the theme The Representation of the Earth, the data analysis gives us valuable information about the existence of a significant difference to 
teach classes using AR or not. In this same process can know the vision that of the technology have students and teachers about the process that allows integrate the use of AR in the classrooms (Kerawalla, Luckin, Seljeflot, \& Woolard, 2006; Di Serio, Ibanez, \& Kloos, 2013).

With the results obtained that reflect an improves in the process of teaching learning and in the performance of them students is can appreciate that is an opportunity that have of pose in them schools, performing experiences similar as which found in all the world (Di Serio, Ibanez, \& Kloos, 2013; Diaz, Hincapie, \& Moreno, 2015; Prendes, 2015; Akcayir, Akcayir, Pektas, \& Ocak, 2016).

Comparing the control group and the experimental group we appreciate that this improvement is more than 4 points out of 10 , so this methodology focused on skills performance. Students and teachers are receptive, this technology seems them motivating and incentives, although the first steps of this deployment presents some technical and creative problems occasionally of and adaptation of the contents, is of special importance to teachers who don't feel ready with the challenge of addressing technical problems, creating content or deal with problems that may arise the various devices, Tablet of different brands and specifications techniques in particular.

While teachers raise these difficulties when it comes to the integration of the AR in their classrooms students accept it naturally, are digital natives and have around us access to devices with relative ease. They mostly have smartphones and access to wifi networks and data for which we should take into account the work of Harley, Poitras, Jarrell, Duffy, \& Lajoie (2016) describing the design recommendations for AR applications and techniques devices that should lead to a standard of use features. Therefore, they would like use AR in the themes if they have the opportunity and it seems a good idea integrated into classrooms.

In this aspect it would have to change the rules of the elementary schools that do not allow the use of these devices. Students say they are less bored with the use of this technology, which seem more interesting content and allowing them to learn by playing, even when the activities and content are not posed as a game (Laine, Nygren, Dirin, \& Suk, 2016). They like and fun use these devices, they know how to use, and no they pose a challenge. They appreciate that helps them work in class, to learn and better understand the explanations of their teacher and get better grades.

As studies of Han, Hyun, \& So (2015) this perception so positive that allows them students is makes necessary enhance the use of this technology in classrooms, integrating in schools, improving contained and facilitating the training of them teaching and giving to them centers of personal technical right. Is necessary to provide future teachers of capabilities, not only for the use of the AR, but also to adapt to a changing technological environment which will present major challenges in the coming years and that demand of teachers an open attitude towards the incorporation of new methodologies and technologies in the classroom, whether AR, Virtual Reality (VR), or those that arise in the coming years.

\section{CONCLUSIONS AND FUTURE WORK}

A qualitative-quantitative methodology is implemented for this work starting from a quasi-experimental design in which a pretest and post-test are administered to the groups. Significant differences were observed in the results after teaching traditionally and using the AR, both in the acquisition of knowledge, translated into an improvement in academic results, and in the perceptions of students and teachers, as well as in the motivation and the interest towards the contents taught with this method. Specific materials were designed for this work and adapted to the devices, contents and number of students. This adaptation effort does not seem to be within the reach of teachers, 
because it requires training in ICT and of specific endowments in the classrooms, both of software and hardware, and of contents. Another aspect is the regulation of the presence of mobile devices in the classrooms, which in our field and currently does not allow the use of Smartphone by the students, but also has no classrooms equipped with this technology in most cases.

The use of mobile devices in households is currently a fact, being able to give the paradox that students have at their disposal available online content that is not used in school or is not present in it, being in many cases adequate. Work is being done on the adaptation of contents to AR and VR, although but this progress is slow. On the other hand, the presence of AR contents in the textbooks will facilitate the task of the teachers who will have at their disposal such contents, as well as AR and virtual reality programs at reasonable prices. Analyze the impact in the classrooms of the AR, the suitability of the contents that appear and its implementation in our classrooms is a task to be done in the coming years.

\section{BIODATA and CONTACT ADDRESSES of AUTHORS}

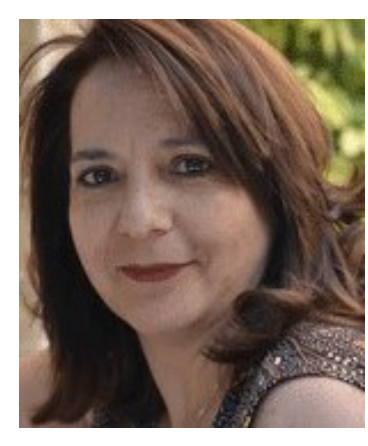

Dr. Purificacion TOLEDO-MORALES is a Professor of Education at University Seville (Spain). Dr. Toledo-Morales gained his Ph. D in Research and Evaluation at December, 1999. Has been teaching preservice teachers for 20 years. Her specializations include distance education, K-12 technology integration, and developing research instrument. His professional interest is harnessing emerging technologies in order to improve and enrich educational and training activities. He has over than 35 journal articles published in international indexes, 50 book chapters national and international, and papers submitted to international meetings.

Purificacion TOLEDO-MORALES

Department of Didactics and Educational Organization

Faculty of Education, University Seville

C/ Pirotecnia s/n, Seville, 41013, SPAIN

Phone: +34 955719285

E-mail: ptoledo@us.es

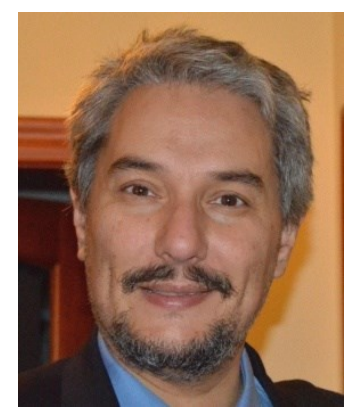

Dr. Jose Manuel SANCHEZ-GARCIA is a Collaborating Professor of Education at University Seville (Spain). Dr. Sanchez-Garcia gained his $\mathrm{Ph}$. D in Research and Technology at December, 2015. His professional interest is harnessing emerging technologies in order to improve and enrich educational and training activities. He is interested in teaching history through the use of educational technologies. He has over than 14 journal articles published in international indexes, 16 book chapters national and international, and papers submitted to international meetings.

\section{Jose Manuel SANCHEZ-GARCIA}

Department of Didactics and Educational Organization

Faculty of Education, University Seville

C/ Pirotecnia s/n, Seville, 41013, SPAIN

Phone: +34 955719285

E-mail: josesanchez@us.es 


\section{REFERENCES}

Akcayir, M., Akcayir, G., Pektas, H.M., \& Ocak, M.A. (2016). Augmented reality in science laboratories: The effects of augmented reality on university students' laboratory skills and attitudes toward science laboratories. Computers in Human Behavior, 57, 334-342, doi:10.1016/j.chb.2015.12.05

Alkhattabi, M. (2017) Augmented Reality as E-learning Tool in Primary Schools' Education: Barriers to Teachers' Adoption. International Journal of Emerging Technologies in Learning, 12(2), 91-100. https://doi.org/10.3991/ijet.v12i02.6158

Azuma, R. (1997). A Survey of Augmented Reality. Presence: Teleoperators and Virtual Environments, 6(4), 355-385. Retrieved from http:// www.cs.unc.edu/ azuma/ARpresence.pdf

Badia, A., Chumpitaz. L., Vargas, J., \& SuArez, G. (2016). La percepcion de la utilidad de la tecnología conforma su uso para ensenar y aprender. Revista Electronica de Investigacion Educativa, 18(3), 95-105. Retrieved from http:// redie.uabc. $\mathrm{mx} /$ redie/article/view/810

Billinghurst, M., Kato, H., \& Poupyrev, I. (2001). The magicbook-moving seamlessly between reality and virtuality. IEEE Computer Graphics and Applications, 21, 6-8.

Chang, R.-C., \& Chung, L.-Y. (2018). Integrating augmented reality technology into subject teaching: The implementation of an elementary science curriculum. Lecture Notes in Electrical Engineering, 422, 187-195. Retrieved from https: / /link.springer.com/chapter/10.1007/978-981-10-3187-8_20

Cheng, K. H., \& Tsai, C. C. (2016). The interaction of child-parent shared reading with an augmented reality (AR) picture book and parents' conceptions of AR learning. British Journal of Educational Technology, 47(1), 203-222, doi:10.1111/bjet.12228

Davis, F.D. (1989). Perceived usefulness, perceived ease of use, and user acceptance of information technology. MIS Quarterly, 13(3), 319-340, doi: 10.2307/249008

Del Moral, E., Villalustre, L., \& Neira-Pinero, M. R. (2016). Minors trapped in the magical world of augmented reality, advergaming and social networks. Prisma Social, (No Especial 1), 0-28. Retrieved from

https://docs.google.com/viewerng/viewer?url=http://www.isdfundacion.org/p ublicaciones/revista/numeros/N_Especial+1/secciones/tematica/pdf/1_nespeci al_minors-social+networks_0-28.pdf

Di Serio, A., Ibanez, M. B., \& Kloos, C. D. (2013). Impact of an augmented reality system on students' motivation for a visual art course. Computers \& Education, 68, 585596, doi:10.1016/j.compedu.2012.03.002

Diaz, C., Hincapie, M., \& Moreno, G. (2015). How the Type of Content in Educative Augmented Reality Application Affects the Learning Experience. Procedia Computer Science, 75, 205-212, doi:10.1016/j.procs.2015.12.239

Dundar, H., \& Akcayir, M. (2012). Tablet vs. Paper: the effect on learners' reading performance. International Electronic Journal of Elementary Education, 4(3), 441-450.

Giasiranis, S., \& Sofos, L. (2017). Flow Experience and Educational Effectiveness of Teaching Informatics using AR. Educational Technology \& Society, 20(4), 78-88. Retrieved from http://www.ifets.info/journals/20_4/8.pdf

Gun, E. T., \& Atasoy, B. (2017). The Effects of Augmented Reality on Elementary School Students' Spatial Ability and Academic Achievement. Education \& Science, 42(191), 31-51. doi:10.15390/EB.2017.7140 
Han, J., Jo, M., Hyun, E., \& So, H.J. (2015). Examining young children's perception toward augmented reality-infused dramatic play. Educational Technology Research and Development, 63(3), 455-474, doi:10.1007/s11423-015-9374-9

Harley, J.M., Poitras, E.G., Jarrell, A., Duffy, M.C., \& Lajoie, S.P. (2016). Comparing virtual and location-based augmented reality mobile learning: emotions and learning outcomes. Educational Technology Research and Development, 64(3), 359-388, doi:10.1007/s11423-015-9420-7

Holley, D., \& Howlett, P. (2016). Engaging Our School Teachers: An Augmented Reality (AR) Approach to Continuous Professional Development. Lecture Notes of the Institute for Computer Sciences, Social-Informatics and Telecommunications Engineering, 160, 118-125, doi: 10.1007/978-3-319-28883-3_15

Huang, T. C., Chen, C. C., \& Chou, Y. W. (2016). Animating eco-education: To see, feel, and discover in an augmented reality-based experiential learning environment. Computers \& Education, 96, 72-82, doi:10.1016/j.compedu.2016.02.008

Huang, Y., Li, H. \& Fong, R. (2015). Using Augmented Reality in early art education: a case study in Hong Kong kindergarten. Early Child Development and Care, 1-16, doi:10.1080/03004430.2015.1067888

Kerawalla, L., Luckin, R., Seljeflot, S., \& Woolard, A. (2006). Making it real: Exploring the potential of Augmented Reality for teaching primary school science. Virtual Reality, 10(3), 163-174, doi:10.1007/s10055-006-0036-4

Laine, T. H., Nygren, E., Dirin, A., \& Suk, H. J. (2016). Science Spots AR: a platform for science learning games with augmented reality. Educational Technology Research and Development, 64(3), 507-531, doi:10.1007/s11423-015-9419-0

Martín-Gutierrez, J., Fabiani, P., Benesova, W., Meneses, M. D., \& Mora, C. E. (2015). Augmented reality to promote collaborative and autonomous learning in higher education. Computers in Human Behavior, 51, 752-761, doi:10.1016/j.chb.2014.11.093

Palmarini, R., Erkoyuncu, J.A., Roy, R., \& Torabmostaedi, H. (2018). A systematic review of augmented reality applications in maintenance. Robotics and ComputerIntegrated Manufacturing, 49, February, 215-228, https://doi.org/10.1016/j.rcim.2017.06.002

Prendes, C. (2015). Realidad aumentada y educacion: anAlisis de experiencias prActicas augmented reality and education: analysis of practical experiencies. Pixel-Bit, 46, 187-203, https://doi.org/10.12795/pixelbit.2015.i46.12

Ruiz-Ariza, A., Casuso, R.A., Suarez-Manzano, S., \& Martínez-Lopez, E.J. (2018). Effect of augmented reality game Pokemon $\mathbf{G O}$ on cognitive performance and emotional intelligence in adolescent young. Computers \& Education, 116, 49-63, https://doi.org/10.1016/j.compedu.2017.09.002

Tanner, P., Karas, C., \& Schofield, D. (2014). Augmenting a child's reality: Using educational tablet technology. Journal of Information Technology Education: Innovations in Practice, 13, 45-54. Retrieved from http://www.jite.org/documents/Vol13/JITEv13IIPp045-055Tanner0464.pdf

Venkatesh, V., \& Bala, H. (2008). Technology acceptance model 3 and a research agenda on interventions. Decision Sciences, 39(2), 273-312.

Wasko, C. (2013). What Teachers Need to Know About Augmented Reality Enhanced Learning Environments. TechTrends, 57(4), 17-21, https://doi.org/10.1007/s11528-013-0672-y

Wu, H.K , Lee, S.W., Chang, H.Y , \& Liang, J.C (2013). Current status, opportunities and challenges of augmented reality in education. Computers \& Education, 62, 41-49. https://doi.org/10.1016/j.compedu.2012.10.024 